\title{
Hour Times Gram per Milliliter per Meter Squared
}

National Cancer Institute

\section{Source}

National Cancer Institute. Hour Times Gram per Milliliter per Meter Squared. NCI

Thesaurus. Code C111213.

Hours times grams per milliliter, divided by meters squared. 